of the fatty acids. Considering only initial and final states between TPNH and $\mathrm{H}_{2} \mathrm{O}$, it is clear that thermogenesis will vary as the work function (potential energy pool) generated along the oxidative pathway. Hence, excluding that portion metabolized via mitochondrial DPNH-dependent pathways, the more thermogenic routes will be those passing by way of the acyl dehydrogenases to the electron transport flavins (ETF) (ref. 13); the latter, coupling through FAD, will exhibit phosphorylative ratios $(\mathrm{P} / \mathrm{O})$ of the order of 2 , that is, a work function of $2 / 3$ of that of $\beta$-hydroxybutyrate and thus thermogenesis in equivalence of $1 \sim \mathrm{P}$.

Whether additional thermogenesis is derived through subsequent utilization of the potential energy ("highenergy') bond pool formed in these reactions is essentially irrelevant to the present argument, since the thermal yield from this source will depend on the efficiency of the mechano-chemical or other coupling and the external work performed by the system. It is, of course, acknowledged that in all transfers, both to and from the potential energy pool, heat losses (thermogenesis) may also be expected, so that in this sense total thermogenesis tends to increase as a function of turnover rate whatever the pathways used.

It is concluded, therefore, that thermogenesis from thyroid action is facilitated by recourse not to uncoupling of mitochondrial oxidative phosphorylation, but rather by emphasis of alternative pathways wherein both DPNH and TPNH are oxidized either by extra-mitochondrial, poorly phosphorylating transfers, or by indirect couplings at lower potential levels of the electron transport chain. Important mediators of this appear as the $\alpha-G-P$ shuttle and a quasi-trans-hydrogenation via the fat depots ${ }^{14}$ and the acyl dehydrogenases.

Robert E. SMith

Department of Physiology,

University of California, Los Angeles

School of Medicine,

I os Angeles 24, California.

1 Pitt-Rivers, R., and Tata, J. R., The Thyroid Hormones (Pergamon Press, New York, 1959).

${ }^{2}$ Smith, R. E., and Hoijer, D., Physiol. Rev., 42, 60 (1962).

- Lee, Y.-P., Takemori, A. E., and Lardy, H. A., J. Biol. Chem., 234, 3051 (1959).

- Lardy, H. A., Lee, Y.-P., and Takemori, A. E., Ann. N.Y. Acad. Sci., 86,

soung, H. L., and Pace, N., Arch. Biochem. Biophys., 76, 112 (1958).

- Lehninger, A. C., Harvey lectures, 49, 176 (1953-4).

'Hoch, E. L., and Lipman, F., Proc. U.S. Nat. Acad. Sci., 40, 909 (1954).

- Hannon, J. P., Rosenthal, A., and Durrer, J. L., Amer. J. Physiol., 204, 515 (1963).

- Reynafarje, B., and Chaffee, R. R. J., Proc. Soc. Exp Biol. and Med., 108,225 (1960).

${ }^{10}$ Fairhurst, A., Roberts, J. C., and Smith, R. E., Amer. J. Physiol., 197,

1 Smith, R. E., Fed. Proc., 19, 64 (1960). 13 Tata, J. R., Ernster, L., Lindberg, O., Arrhenius, E., Pedersen, S., and

13 Lynen, F., and Decker, K., Ergebn. de Physiol., 49, 327 (1957).

14 Smith, R. E., Fed. Proc., 22, 738 (1963).

\section{Trigeminus Reflex in Young Infants}

A WEAk electrical stimulus on the receptive field of N. trigominus (parts II and III) in infants between a few weeks and 12 months old is followed by a discharge in the nerves of the muscles, biceps and triceps brachii, and biceps and quadriceps femori, without any visible movement. The activity of these muscles is synchronized. No reciprocal pattern could be detected. We found two groups of latencies-one with a maximum at $140 \mathrm{msec}$ and a second between 300 and $400 \mathrm{msec}$ (Fig. 1). Stimula. tion of regions other than that supplied by the trigeminal nerve is without effect, unless the stimulus is very strong -a fact which is in accordance with the work of Hooker ${ }^{1}$ on human foetuses. We suppose that the myographically.

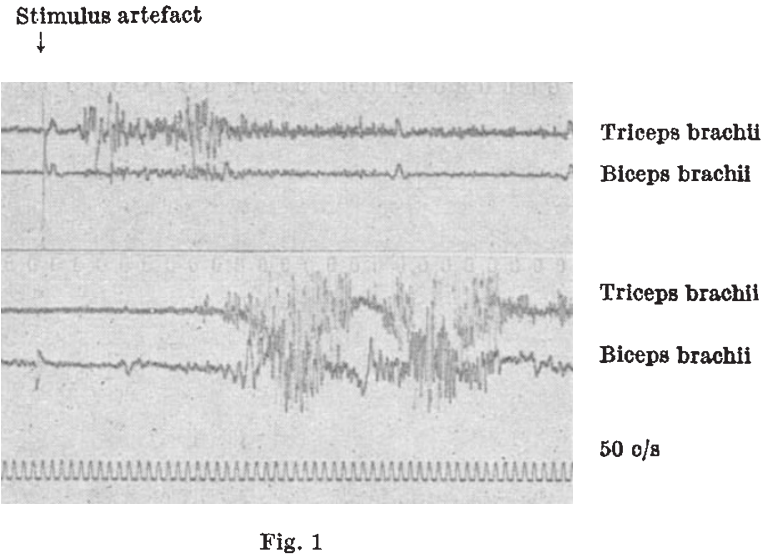

tested reactions of muscles of the extremities have nothing to do with the Moro-reflex, or common fright reaction, which is often seen after very strong visual, acoustic or tactile stimulation.

This work was supported by a grant from the Deutsche Forschungsgemeinschaft.

\section{H. C. HopF \\ H.-J. HUFSCHMIDT \\ J. STRÖDER}

Neurological Clinic,

University of Würzburg.

${ }^{1}$ Hooker, D., Res. Publ. A88, Nerv. Ment. Dis,, 33, 88, 113 (1954).

\section{Potassium-free Effect in Squid Axons}

Previous work ${ }^{1}$ has shown that the sodium efflux from squid giant axons is sensitive to the external concentration of potassium ions; the Na efflux falls to about $1 / 3$ of control values when the sea water surrounding the axon is made free from potassium. Similar observations have been made with frog sartorius muscle ${ }^{2}$, but these showed further that when $[\mathrm{Na}]_{i}$ in muscle was low, $\mathrm{Na}$ efflux was no longer sensitive to external [K]. The following experiments were undertaken to see if the $\mathrm{Na}$ efflux from squid axons would be similarly insensitive to $\left[\mathrm{K}_{0}\right]$ if $[\mathrm{Na}]_{t}$ were low.

Preliminary trials showed that two different methods yielded giant axons with a low $[\mathrm{Na}]_{i}$. In the first, axons were immersed for $6 \mathrm{~h}$ in $400 \mathrm{mM} \mathrm{KCl}+50 \mathrm{mM} \mathrm{CaCl}$ solution with the $p \mathrm{H}$ adjusted to 8.0 with tris. Such axons had, on analysis, $[\mathrm{Na}]_{i}$ of about $35 \mathrm{mM}$. In a second method, axons were stimulated in normal sea water with all $\mathrm{Na}^{+}$replaced by $\mathrm{Li}^{+}$for $0.5 \mathrm{~h}$ at $60 / \mathrm{sec}$. An analysis of the axoplasm of 7 axons subjected to stimulation in Li-sea water showed the following mean values: $[\mathrm{Na}]_{i}=36,[\mathrm{~K}]_{i}=158,[\mathrm{Li}]_{i}=117 \mathrm{~m}$.mole/l. Other (unpublished) measurements from our laboratory for fresh axoplasm showed a value for $[\mathrm{Na}]_{1}$ of about 70 $\mathrm{mM}$ so that both experimental treatments reduced $[\mathrm{Na}]_{i}$ to about half that of fresh axoplasm. Because the experimental procedures involved much time and axon survival was judged to be a critical factor in their success or failure, the stimulation in Li method was chosen for all the measurements to be reported. The $[\mathrm{Li}]_{i}$ found above can be compared with an entry of $\mathrm{Li}$ of $43 \mu \mathrm{mole} / \mathrm{g}$ calculated on the basis of a resting influx of 50 pmole $\mathrm{cm}^{2} \mathrm{sec}$ for the $3 \mathrm{~h}$ that the axon was isolated and using a factor of $80 \mathrm{~cm}^{-1}$ for the surface : volume ratio of a $500 \mu$ axon. To this must be added $69 \mu \mathrm{mole} / \mathrm{g}$ resulting from stimulation at $60 / \mathrm{sec}$ for $30 \mathrm{~min}$ and using a value of net $\mathrm{Li}$ flux of $6 \mathrm{pmole} / \mathrm{cm}^{2}$ impulse as appropriate to a temperature of $10^{\circ} \mathrm{C}$. The sum of the stimulated and resting entry yields a final [Li] $]_{i}$ of $112 \mathrm{mM}$, which is quite close to the value obtained from analysis. It might 